Research Article

\title{
Formation Mechanism and the Height of the Water-Conducting Fractured Zone Induced by Middle Deep Coal Seam Mining in a Sandy Region: A Case Study from the Xiaobaodang Coal Mine
}

\author{
Xiaoshen Xie $\mathbb{D}^{1,},{ }^{1,2}$ Enke Hou $\mathbb{D}^{1,2}$ Shuangming Wang ${ }^{1}{ }^{1,2}$ Xueyang Sun, ${ }^{1,2}$ Pengfei Hou, ${ }^{1,2}$ \\ Shibin Wang, ${ }^{3}$ Yongli Xie, ${ }^{4}$ and Yongan Huang ${ }^{5}$ \\ ${ }^{1}$ College of Geology and Environment, Xi'an University of Science and Technology, Xi'an, Shaanxi 710054, China \\ ${ }^{2}$ Shaanxi Provincial Key Laboratory of Geological Support for Coal Green Exploitation, Xi'an, Shaanxi 710054, China \\ ${ }^{3}$ Shaanxi Coal Industry Company Limited, Xi'an, Shaanxi 710077, China \\ ${ }^{4}$ Shaanxi Xiaobaodang Mining Company Limited, Shenmu, Shaanxi 719302, China \\ ${ }^{5}$ SHCCIG Yubei Coal Industry Company Limited, Yulin, Shaanxi 719000, China
}

Correspondence should be addressed to Xiaoshen Xie; xxswpp0816@163.com and Enke Hou; houek@xust.edu.cn

Received 29 December 2020; Revised 26 February 2021; Accepted 11 March 2021; Published 1 April 2021

Academic Editor: Chong Xu

Copyright (c) 2021 Xiaoshen Xie et al. This is an open access article distributed under the Creative Commons Attribution License, which permits unrestricted use, distribution, and reproduction in any medium, provided the original work is properly cited.

\begin{abstract}
The height of the water-conducting fractured zone (WCFZ) is a basic parameter related to water protection in coal mines and is also crucial for aquifer protection and mine safety. In order to accurately detect the height and shape and reveal the formation mechanism of the WCFZ, which is caused by middle-deep coal seam mining in a sandy region, the 112201 coalface at the $1 \#$ coal mine of Xiaobaodang was taken as a case study. Filed measurements including fluid leakage, borehole TV, and similar simulation were adopted to analyze the regularity of the WCFZ in this area. The detection results of field measurements showed that the maximum height of the WCFZ was $177.07 \mathrm{~m}$ in a borehole near the open-off cut, and the ratio of the height of the waterconducting fractured zone divided by the mining thickness was 30.53 . The WCFZ acquired an inward-convergent saddle shape, which was inclined to the goaf. The saddle bridge was located at the boundary of the goaf, and the saddle ridge was located at the center of the goaf. Also, through analyzing the results of similar simulations, we found that, in the process of mining, separation cracks and the beam structure were the main forms of overburden disturbance transmitting upward and ahead of mining, respectively. The main cause of the increase in height of the WCFZ was the connection of the separation cracks and vertical cracks caused by fractures of beam structures. The development of the WCFZ was divided into five stages: incubation stage, development stage, rapidly increasing stage, slowly increasing stage, and stable stage. Moreover, the duration of each stage was related to the lithology and mining technology. This research can provide significant theoretical insights for the prediction of the WCFZ, enabling the prevention of water hazards on mine roofs and assisting with water resources protection.
\end{abstract}

\section{Introduction}

Coal, the primary energy source in China, plays an important role in its economic development and energy security $[1,2]$. In 2019 , the coal production was 3.85 billion tons and accounted for $57.7 \%$ of Chinese total energy consumption. Raw coal production increased by $4.0 \%$ from 2018 to 2019. Therefore, coal will likely be the main source in China for a long time $[3,4]$.
Previous studies have shown that a few geological environmental disasters, such as overburden movement, surface crack, and loss of groundwater resources, have been caused by coal mining [5-8]. In particular, the loss of groundwater resources related to the water-conducting fractured zone (WCFZ) caused by mining is the focus of ecological environmental protection.

When a coalface is mined, the strata lying above the goaf will move and deform. As the displacement value exceeds 
the limit value, cracks are generated. Once cracks at different heights connect, the water-conducting fractured zone is formed $[9,10]$. The connected cracks in the water-conducting fractured zone that is formed are the main channels conducting water inrushes that lead to sand collapse $[11,12]$. Thus, it is of great significance to study the development characteristics and formation mechanisms of the WCFZ during mining, especially determining the height and shape and clarifying the formation mechanisms of the waterconducting fractured zone.

To date, many studies about the WCFZ have been carried out by many scholars. Feng et al. [13] found the relationship between a rock layer's tensile ratio and the height of the WCFZ and established a predicted model for the height of the WCFZ. Liu et al. [14] revealed the relation between the mining height, the excavation rate, the hard rock ratio coefficient $(\mathrm{K})$, and the height of the WCFZ using 20 groups of data. Meanwhile, analyzing drilling data, Wang et al. found that the height of WCFZ induced by longwall mining was 18 to 28 times the mining thickness of the coal seam north of Shaanxi province. Gu et al. [15] found a way of predicting the height of WCFZ based on the location of key stratum (KS). Zhang et al. [16] adopted three methods to observe the height of a WCFZ, including borehole water leakage, borehole TV images, and numerical simulation. Methods that have been used to study the development law of the WCFZ include various numerical simulation methods, such as rock failure process analysis (RFPA) $[17,18]$, Universal Distinct Element Code (UDEC) $[1,19,20]$, Fast Lagrange Analysis of Continua (FLAC) [12], Particle Flow Code (PFC) [21], and the similar-material simulation method [22]. Also, borehole TV and an electrical logging drilling fluid loss observation system have been adopted to observe the height of the WCFZ.

Although previous studies have much work in safe mining, however, due to large variations in geological conditions, the development laws of the WCFZ in different coal mines vary significantly. Also, the height of the WCFZ is also varied at different positions in a working face. In addition, few studies have focused on the shape of the WCFZ. So to reveal the formation mechanism of the height and shape of the WCFZ caused by middle-deep coal seam mining, we studied the 112201 coalface in the $1 \#$ coal mine of Xiaobaodang using a similar-material simulation and field measurements. This study aimed to discover the movement characteristics of overburden, and the law and mechanism of the WFCZ with coal mining, to provide a theoretical support for the prevention of roof water disasters and to help protect the ecological environment around the Xiaobaodang coal mine.

\section{Background}

The $1 \#$ coal mine of Xiaobaodang lies in the middle of the Yushenfu mining area in the north of the Loess Plateau and the southeast edge of the Maowusu Desert in Northern Shaanxi Province. The elevation of the ground surface ranges from $1,198 \mathrm{~m}$ to $1,346 \mathrm{~m}$, and the relative elevation difference is $148 \mathrm{~m}$. The climate is typical mid-temperate semiarid continental, and the average annual rainfall is $583 \mathrm{~mm}$, concentrated mainly in July, August, and September. The ground surface is mainly covered by the aeolian sand of Quaternary, and the ground vegetation mainly includes Artemisia sphaerocephala, Salix psammophila, cypress, and weeds that have grown to resist wind and sand.

The 112201 coalface, with a strike length of $4560 \mathrm{~m}$ and an inclined length of $350 \mathrm{~m}$, is the first working face of the $1 \#$ coal mine of Xiaobaodang and belongs to the first mining area. The geological reserves of coal are 12.4467 million tons, and the recoverable reserves are 12.0733 million tons. The ground elevation ranges from $1,283 \mathrm{~m}$ to $1,330 \mathrm{~m}$. The ground surface is mainly covered by loose sand. A few surface ponds have developed on low-lying areas. Figure 1 shows the location of the coal mine and the 112201 coalface.

Figure 2 shows the strata histogram of the 112201 coalface. The thickness of the $2^{-2}$ \# coal seam is $4.2 \mathrm{~m}$ to $6.3 \mathrm{~m}$, with an average thickness of $5.8 \mathrm{~m}$. The buried depth of the coal seam is 295 to $380 \mathrm{~m}$, with an average buried depth of $302 \mathrm{~m}$. The overlying bedrock, which is composed primarily of finegrained sandstones and siltstone, is $180 \mathrm{~m}$ to $260 \mathrm{~m}$ thick; the average thickness is $215 \mathrm{~m}$. The formation above the bedrock is the red soil layer with an average thickness of $65 \mathrm{~m}$. Unconsolidated Quaternary soil with an average thickness of $8.5 \mathrm{~m}$ overlies the red soil layer. In addition, the lithology test data show that the bedrock layer above the $2^{-2}$ \# coal seam has a moderately hard lithology, and the unconsolidated Quaternary soil is relatively loose and weak.

The 112201 coalface was advanced using the longwall mining method from 2018-09-10 to 2019-08-12. The mining thickness of the $2^{-2}$ \# coal seam ranged from $5.4 \mathrm{~m}$ to $6.1 \mathrm{~m}$ ( $5.8 \mathrm{~m}$ on average), and the roof was managed by the allcaving method.

\section{Height Analysis of the Water-Conducting Fractured Zone}

\subsection{Field Measurements}

3.1.1. Locations of Monitoring Holes. In order to study the height and shape of the WCFZ caused by the 112201 coalface mining, fluid leakage and borehole TV technologies were adopted to explore the development of the WCFZ. On the basis of two ground boreholes that were drilled one year ago in the 112201 working face, three boreholes were located at different distances from the installed open-off cut. The XSD4 borehole was $20 \mathrm{~m}$ from the open-off cut. To detect the shape and height of the WCFZ in the dip direction of the coalface, the XSD 5 borehole was arranged on the coal pillar of the belt way. The horizontal distance between XSD5 and XSD1 was $30 \mathrm{~m}$. XSD1 and XSD2 were located at $400 \mathrm{~m}$ from the openoff cut. XSD1 was near the belt way, and XSD2 was in the middle of the face. The detection line in the dip direction was formed by XSD1, XSD2, and XSD5 boreholes, and the detection line in the strike detection was set up by the XSD2, XSD4, and XSD6 boreholes. The height of the WCFZ was mainly evaluated by the fluid leakage, water level, and borehole TV. Figure 3(d) shows the location of the boreholes. 

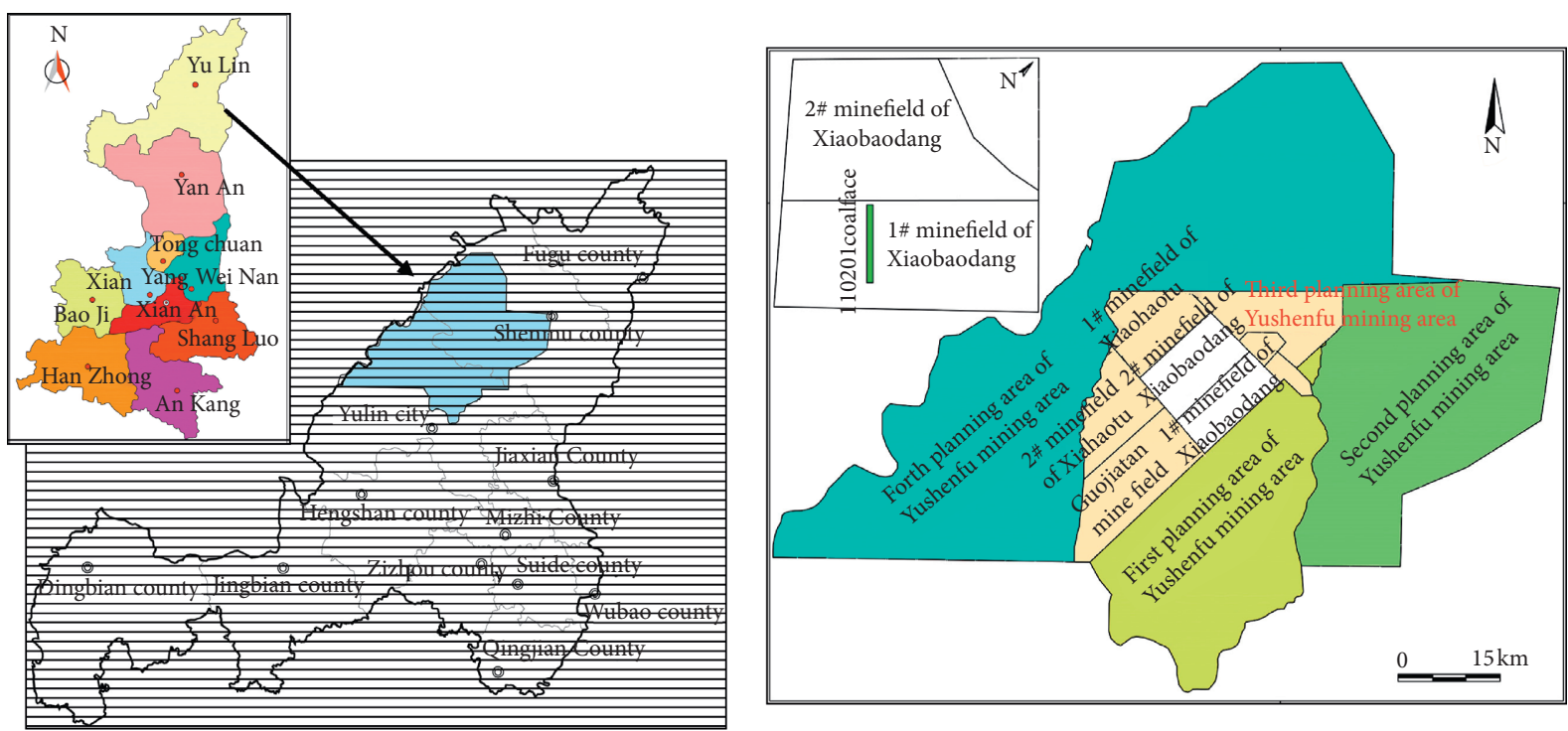

FIGURE 1: Location of the study area.

\begin{tabular}{|c|c|c|c|}
\hline $\begin{array}{c}\text { Serial } \\
\text { number }\end{array}$ & Bar graph & $\begin{array}{c}\text { Thickness } \\
(\mathrm{m})\end{array}$ & Lithology description \\
\hline 1 & $\because$. & \multirow{2}{*}{$\frac{3.3 \sim 29.24}{8.50}$} & Yellow sandy, loose \\
\hline 2 & & & Yellow, fine sand less, loose \\
\hline 3 & & $\frac{50.0 \sim 90.0}{65.00}$ & $\begin{array}{l}\text { Clay, purple red, } \\
\text { swelling in water }\end{array}$ \\
\hline 4 & 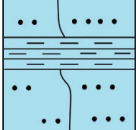 & $\frac{30.0 \sim 90.0}{52.30}$ & $\begin{array}{l}\text { Lithology: mudstone, siltstone } \\
\text { Gray-white, massive, }\end{array}$ \\
\hline 5 & \begin{tabular}{|c|}
$\cdots$ \\
$\cdots$ \\
$\cdots$ \\
$\cdots$ \\
\end{tabular} & $\frac{50.0 \sim 90.0}{80.30}$ & $\begin{array}{l}\text { Composed of mudstone, siltstone } \\
\text { and arkose greywacke } \\
\text { Gray-white, massive, dark, muddy } \\
\text { cementation, medium hard }\end{array}$ \\
\hline 6 & $\frac{\cdots}{\cdots}$ & $\frac{79.8 \sim 130}{98.30}$ & $\begin{array}{l}\text { Lithology: medium grained sandstone, } \\
\text { coarse grained sanstone, mudstone } \\
\text { siltstone and coal seam } \\
\text { Gray-white, massive, dark, muddy } \\
\text { cementation, medium hard, rhombic }\end{array}$ \\
\hline 7 & & 5.8 & $2^{-2}$ coal; brown-black massive, dim \\
\hline
\end{tabular}

FIgURE 2: The overburden strata histogram of the $2^{-2}$ \# coal seam.

3.1.2. Results of Field Measurements. Variations in fluid leakage and outcomes of the borehole TV in three boreholes are shown in Figure 3. Figure 3(a) shows that when the drilling depth of XSD4 was less than $95 \mathrm{~m}$, fluid leakage ranged from 0.0 to $0.46 \mathrm{~L} / \mathrm{s}$ (average value of $0.16 \mathrm{~L} / \mathrm{s}$ ), indicating that no crack was induced by mining in that section. When the drilling depth is greater than $95 \mathrm{~m}$, fluid leakage rose to $1.95 \mathrm{~L} / \mathrm{s}$ suddenly, and within a range of $96 \mathrm{~m}$ to $124.8 \mathrm{~m}$ of the drilling depth, the average value of fluid leakage was increased to $0.95 \mathrm{~L} / \mathrm{s}$. When the drilling depth exceeded $124.8 \mathrm{~m}$, flushing fluid leaked out $(3.21 \mathrm{~L} / \mathrm{s})$ and no longer circulated, indicating that the drill had entered the WCFZ. The depth of $124.8 \mathrm{~m}$ was inferred as the top boundary of the WCFZ according to the result of the fluid leakage analysis. Also, photographs taken by the XSD4 borehole TV showed that the inner wall of the borehole was smooth and without cracks when the drilling depth was less than $123.3 \mathrm{~m}$. When the drilling depth was greater than $123.3 \mathrm{~m}$, vertical cracks started to develop. As the borehole drilling continued, the number of vertical cracks and their widths increased. Thus, the depth of $123.3 \mathrm{~m}$ was considered to be the top boundary of the WCFZ. Combining the two results, a depth of $123.3 \mathrm{~m}$ was finally determined to be the top boundary of the WCFZ of the XSD4 borehole. The height of the WCFZ was calculated by

$$
H_{w}=H-D,
$$

where $H_{w}$ is the height of the WFCZ $(\mathrm{m}), H$ is the vertical depth between the borehole and the coal seam roof $(300.4 \mathrm{~m})$, and $D$ is the vertical depth between the top boundary of the WCFZ and the borehole $(123.3 \mathrm{~m})$.

The height of the WCFZ of the XSD4 borehole, as calculated using Equation (1), was $177.1 \mathrm{~m}$.

The detected results of the WCFZ of the XSD5 borehole are shown in Figure 3(b). The fluid leakage was relatively stable, with an average value of $0.083 \mathrm{~L} / \mathrm{s}$ when the drilling depth was less than $229.4 \mathrm{~m}$. However, fluid leakage suddenly reached the maximum value when a drilling depth of $229.4 \mathrm{~m}$ was exceeded. On the basis of the rate of fluid leakage, it can be considered that a depth of $229.4 \mathrm{~m}$ was the top boundary for the WCFZ. Moreover, borehole TV photographs within the depth range of $221 \mathrm{~m}$ to $231 \mathrm{~m}$ showed that the depth at which separation cracks began to develop was $222.3 \mathrm{~m}$, and the number of separation cracks 


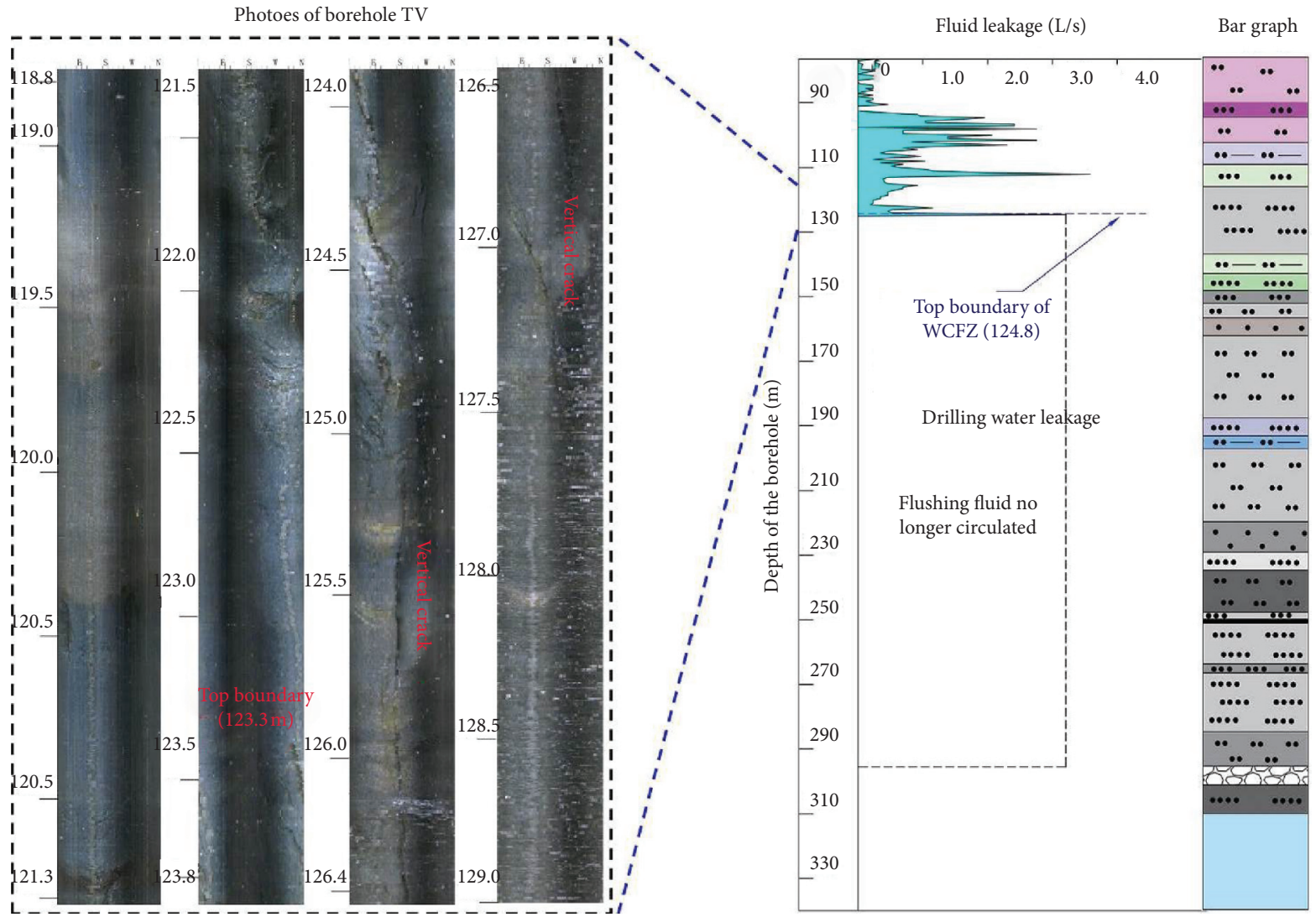

(a)

Photoes of borehole TV

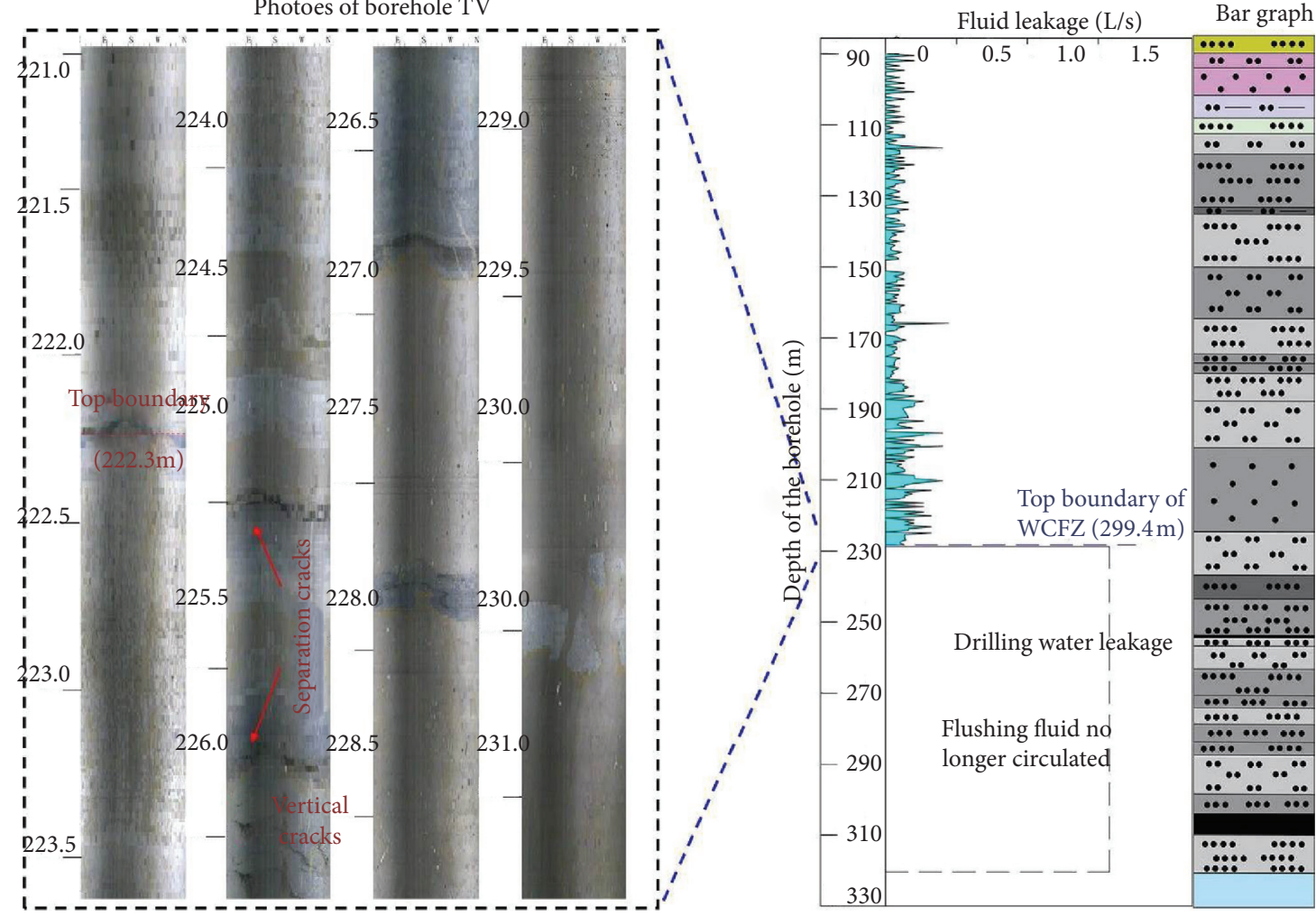

(b)

Figure 3: Continued. 
Photoes of borehole TV

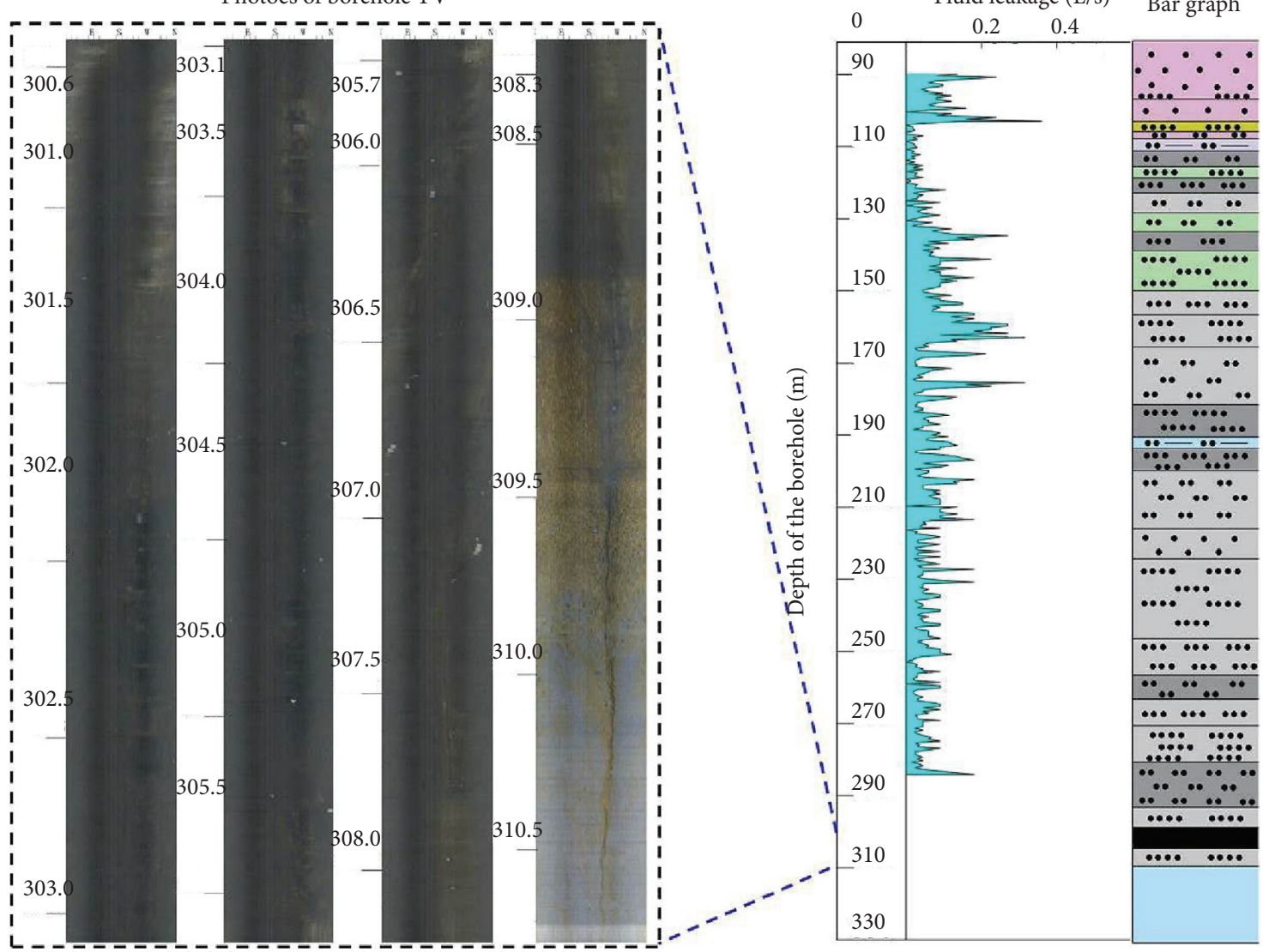

(c)

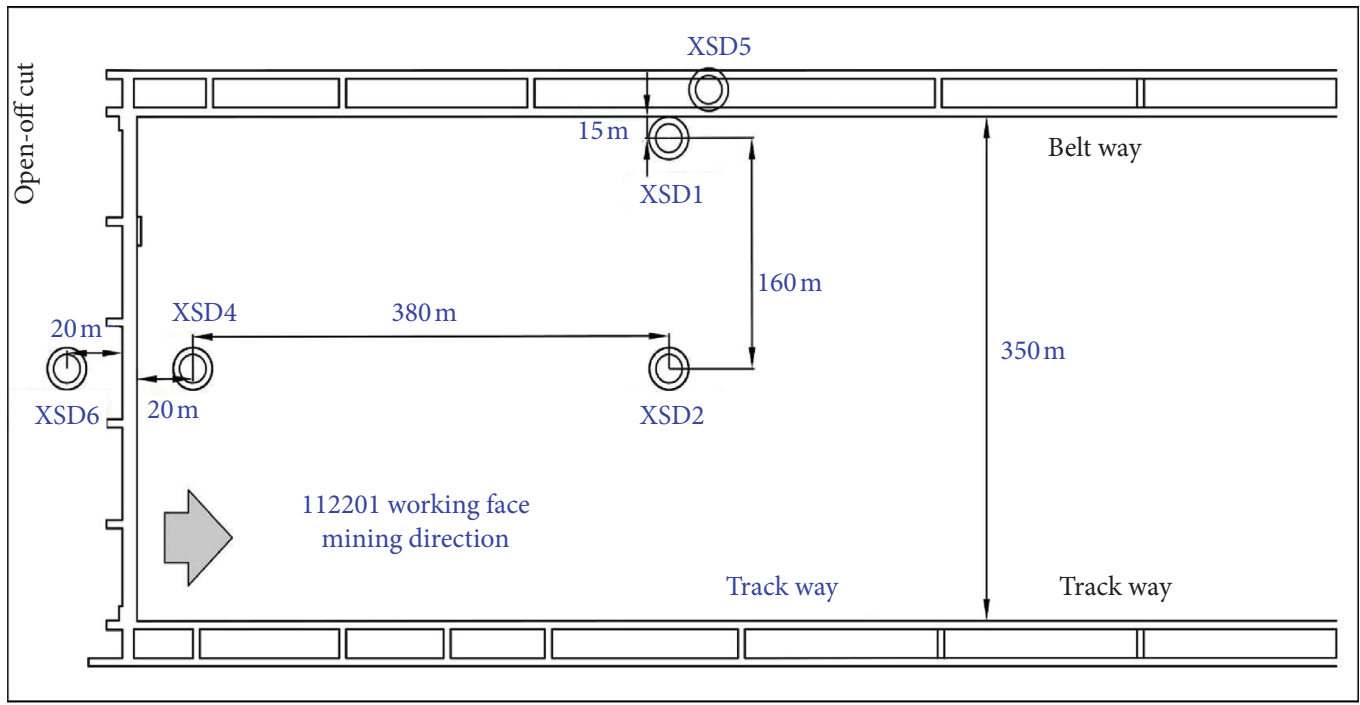

(d)

FIGURE 3: Detection results of boreholes. (a) XSD4 borehole, (b) XSD5 borehole, (c) XSD6 borehole, and (d) location map of boreholes.

increased gradually with an increase in drilling depth. Therefore, the depth of $222.3 \mathrm{~m}$ was interfered to be the top boundary of the WCFZ in the XSD5 borehole. The height of the WCFZ was $81.5 \mathrm{~m}$ in the XSD5 borehole, which was calculated by applying Equation (1).
Figure 3(c) shows that fluid leakage was generally low, with an average value of $0.17 \mathrm{~L} / \mathrm{s}$, in the depth range of 90 to $283 \mathrm{~m}$; there was no sudden remarkable change, indicating that no cracks in the XSD6 borehole were caused by mining. Also, the borehole TV photographs showed that the wall was 
smooth and without cracks. Hence, the height of the WCFZ in the XSD6 borehole was $0 \mathrm{~m}$.

Through analyzing the data, it was found that the heights of the WCFZ measured in the XSD1 and XSD2 boreholes were $158.8 \mathrm{~m}$ and $157.1 \mathrm{~m}$, respectively.

In summary, the heights of the WCFZ in the XSD1, $\mathrm{XSD} 2, \mathrm{XSD} 4, \mathrm{XSD} 5$, and XSD6 boreholes were $158.8 \mathrm{~m}$, $157.1 \mathrm{~m}, 177.1 \mathrm{~m}, 81.5 \mathrm{~m}$, and $0.0 \mathrm{~m}$, respectively (see Table 1). As can be seen from the detection results, the maximum height of the WCFZ was $177.07 \mathrm{~m}$, and the maximum ratio of the height of the WCFZ $\left(H_{w}\right)$ to mining thickness $(M)$ was 30.53 , which can be adapted to forecast the height of the WCFZ caused by other instances of coalface mining at the $1 \#$ coal mine of Xiaobaodang.

On the basis of the detection results, the morphology of the WCFZ was drawn, as shown in Figure 4. It can be seen that, along the mining direction, the WCFZ presents a halfsaddle shape, and the saddle bridge was located inside the open-off cut (Figure 4(a)). Perpendicular to the mining direction, the shape of the WCFZ was a saddle, and the saddle bridge was close to the belt way and track way Figure 4(b). The shape of the WCFZ in the 112201 coalface was different from that caused by the shallow seam mining or that detected by numerical simulation, which indicating that the shape of the WCFZ is related to the size of the coalface, mining speed, mining technology, lithology, and so on.

\subsection{Mechanism Analysis of Overburden Failure}

3.2.1. Similar Material Model. To study the development patterns of the WCFZ at various mining distances, a similarmaterial model with a similarity ratio of $1: 250$ was constructed using the method of plane stress. This model was based on the geological conditions of the 112201 coalface, as shown in Figure 5. To facilitate the modelling, the strata thickness was given a set integer, and the similar-material model size was $2.0 \mathrm{~m} \times 1.5 \mathrm{~m}$. The total thickness of the strata was simulated to be $375 \mathrm{~m}$. The $2^{-2}$ coal seam is designed to be mined, and the mining thickness is $6 \mathrm{~m}$. To eliminate boundary effects, a protective $10 \mathrm{~cm}$ thick coal pillar was left on both sides of the model. Each mining step was $10 \mathrm{~cm}$ to correspond to the actual mining distance of $25 \mathrm{~m}$, and the total mining distance of $160 \mathrm{~cm}$ represented the actual distance of $400 \mathrm{~m}$. Six rows of monitoring points were set above the $2^{-2}$ coal seam to monitor the movement and deformation of strata during excavation. Table 2 describes the mixing ratios of experimental materials, calculated according to the similarity ratio.

3.2.2. Results of the Similar Simulation. Figure 6 shows the development patterns and failure characteristics at various advancing distances. When the working face advanced to $75 \mathrm{~m}$, the basic roof, which was $11 \mathrm{~m}$ from the open-off cut, collapsed with a caving angle of $45^{\circ}$ for the first time, and the height of the WCFZ was $9.75 \mathrm{~m}$. With the working face moving continuously, the damage degree of the overburden rock movement was intensified, and the height of the WCFZ
TABLE 1: The height of the WCFZ results of the 112201 coalface by different methodologies.

\begin{tabular}{lcccc}
\hline Boreholes & \multicolumn{4}{c}{ Height of the WCFZ/m } \\
& $\begin{array}{c}\text { Fluid } \\
\text { leakage }\end{array}$ & $\begin{array}{c}\text { Borehole } \\
\text { TV }\end{array}$ & $\begin{array}{c}\text { Comprehensive } \\
\text { results }\end{array}$ & $H w / M$ \\
\hline XSD1 & 158.78 & 154.01 & 158.78 & 27.38 \\
XSD2 & 157.08 & 152.01 & 157.08 & 27.08 \\
XSD4 & 175.57 & 177.07 & 177.07 & 30.53 \\
XSD5 & 74.4 & 81.5 & 81.5 & 14.05 \\
XSD6 & 0 & 0 & 0 & 0.00 \\
\hline
\end{tabular}

increased gradually. When the excavation was at $87.5 \mathrm{~m}$, the roof collapsed again with a $45^{\circ}$ caving angle at the open-off cut; the caving angle of the advanced position was $38^{\circ}$. Meanwhile cracks began to appear in the strata above the $2^{-2}$ coal seam parallel to the mining direction, due to the difference in subsidence. With the working face advancing, the number of cracks parallel to the mining direction increased, and the middle part of the overburden above the $2^{-2}$ coal seam began to develop cracks that were vertical to the mining direction, Then, the strata near the goaf collapsed along the vertical cracks, and the failure height of the overburden rock increased. When the working face advanced to $125 \mathrm{~m}$, vertically discontinuous cracks appeared on both sides of the boundary, and the height of the WCFZ was $60.0 \mathrm{~m}$. With the subsidence of the upper strata, the separation cracks generated by the previous excavation disappeared, and new separation cracks appeared. As the coal seam was mined to $150 \mathrm{~m}$, the roof collapsed again, and the caving step distance was $42.5 \mathrm{~m}$. A few new separation cracks on the overlying strata developed due to the large caving step distance, and the height of the WCFZ was $75.0 \mathrm{~m}$. With the working face advancing, the progress of the bending, cracking, and breaking of the overburden above the $2^{-2}$ coal seam occurred repeatedly, and the height of the overburden failure no longer developed upward from the working face; it advanced to $350 \mathrm{~m}$ and stopped. At the end of the mining, the caving zone height was approximately $47.5 \mathrm{~m}$, and the height of the WCFZ was $177.5 \mathrm{~m}$.

(1) Law of Collapse of Overburden Strata. Figure 7 shows the overlying strata migration process of $2^{-2}$ coal seam mining according to the similar-material simulation results. During the process of coal mining, the roof overburden stratum (layer II) was bent and subsided under the action of gravity. When the subsidence value exceeded the limit of the rock mass, the first breaks appeared in the roof strata, and the caved zone began to develop. With the collapse of the roof overburden stratum (layer II), the subsidence value of the strata above the collapsed body (layers III and IV) gradually increased, and vertical cracks caused by tensile stresses began to appear at the coal pillars on both sides and in the middle of the strata. When the goaf area was large enough, layer III failed and collapsed, and the height of the caved zone increased. Also, the masonry beam and cantilever beam structure, which played a temporary supporting role for the overlying strata, were formed in the advanced position. The record results show that when the working face advanced to $75 \mathrm{~m}$, the roof strata appeared to break for the 


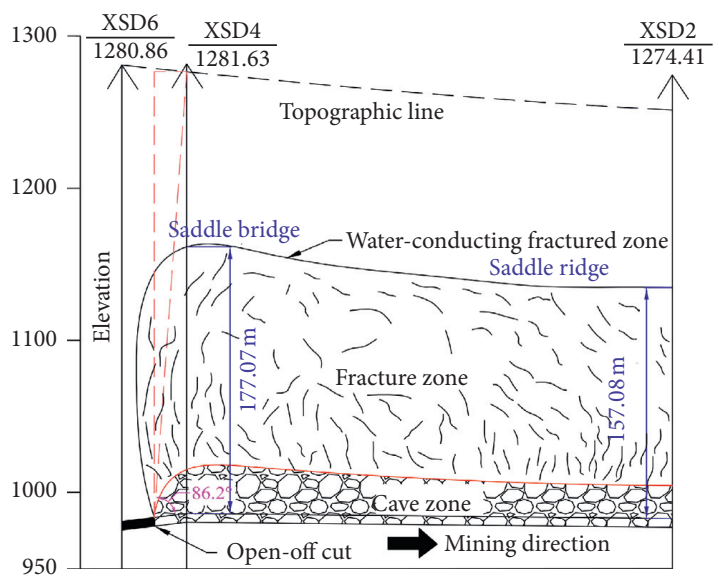

(a)

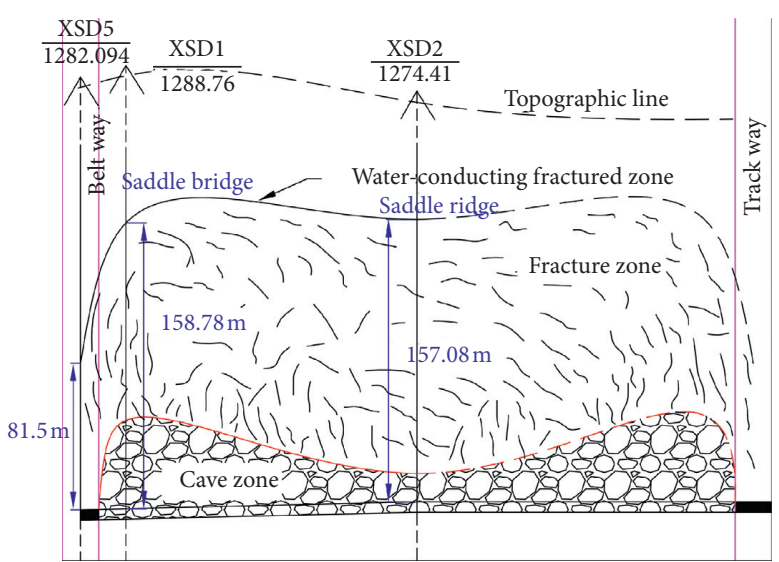

(b)

FIGURE 4: The shape of the WCFZ, (a) the shape of the WCFZ along the mining direction, and (b) the shape of the WCFZ on the inclination.

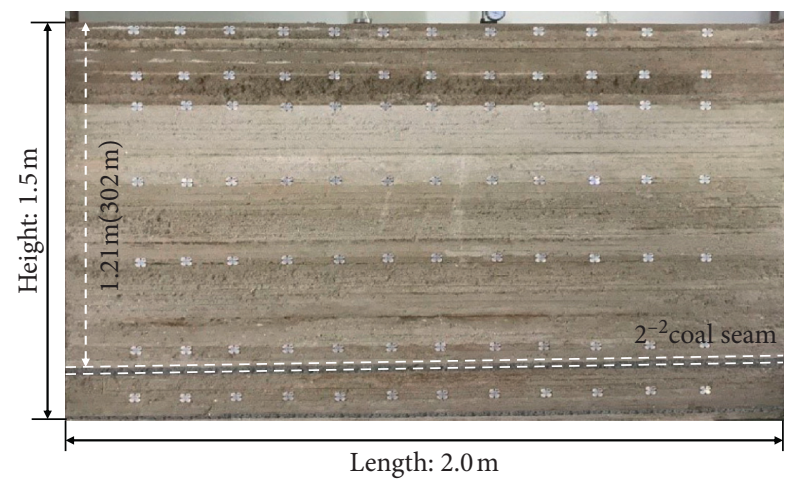

FIGURE 5: Similar material model of the 112201 working face.

first time. When the working face advanced from $75 \mathrm{~m}$ to its end, there were approximately 14 incidents of periodic breaks, the periodic break step distance ranged from $12.5 \mathrm{~m}$ to $42.5 \mathrm{~m}$, and the average periodic break step distance was $26.7 \mathrm{~m}$, which was basically consistent with the measured average step distance $(25.4 \mathrm{~m})$ of the 112201 coalface.

Finally, the caving height of the overburden was $47.5 \mathrm{~m}$, and the ratio of the caving zone height to the thickness of the coal seam was 7.91 .

(2) Development Law of Cracks. Vertical cracks and separation cracks were the two kinds of cracks in the strata. Separation cracks were caused by the uneven bending and subsidence of adjacent rock layers; the characteristic of the separation crack width was a single peak activity that first increased and then decreased. During the advancing process, the width of the separation crack that had developed at the interface of adjacent strata first increased gradually at first. However, when the disturbance caused by the mining affected the strata above the separation crack, the width of the separation crack decreased gradually because of the subsidence of the strata (layers VI and VII). The vertical cracks that developed in the strata above the boundary, also known as upward cracks, were the result of the tensile limit of the strata being broken by tensile force. During the advancing process of the working face, the vertical cracks gradually expanded upward, increased in length, and then connected with the separation cracks.

\subsubsection{Development Law of the Water-Conducting Fractured} Zone. As shown in Figure 8, with the advancing of the working face, there were five stages for the WCFZ: incubation stage, development stage, rapidly increasing stage, slowly increasing stage, and stable stage.

(1) Incubation stage: after the start of the advancing of the working face, the roof strata began to bend and subside. In that period of time, the roof strata did not collapse because the collapse distance limit was not exceeded. The duration of the incubation stage depended on the first collapse step of the roof, which related to the structure of the overburden strata, its lithology, and its mining height.

(2) Development stage: after the incubation stage, as the coal was mined, the value of the subsidence of the roof strata increased gradually. Once the value exceeded the limit, the roof began to collapse as a function of the weight, and the caved zone began to develop. In the early period of the development stage, the WCFZ developed rapidly because an effective masonry beam supporting structure had not been formed by the collapsed rock. As time went on, the effective masonry beam supporting structure was formed by the collapsed rocks that filled in the goaf; this slowed the failure speed of the overburden rock, and the height of the WCFZ increased slowly.

(3) Rapidly increasing stage: with the mining of the coal seam, more and more strata (including key strata) were affected, and the beam structure formed by the fractured rocks continued to break and collapsed under the heavy pressure of the overlying strata. When the key strata were broken, many vertical cracks and separation cracks developed rapidly, which led to a rapid rise in the height of the WCFZ. 
TABle 2: Parameters and the material ratio of the similar model.

\begin{tabular}{|c|c|c|c|c|c|c|c|c|}
\hline \multirow{2}{*}{ Stratum } & \multirow{2}{*}{ Model thickness $(\mathrm{cm})$} & \multirow{2}{*}{ Proportioning mass $(\mathrm{kg})$} & \multicolumn{3}{|c|}{ Simulation material ratio } & \multicolumn{3}{|c|}{ Mass of simulated material $(\mathrm{kg})$} \\
\hline & & & Sand & Gypsum & White powder & Sand & Gypsum & White powder \\
\hline Soil layer & 31 & 206 & & & & & & \\
\hline Mudstone & 2 & 13 & 7 & 3 & 7 & 9.3 & 1.2 & 3.6 \\
\hline Fine sandstone & 5 & 33 & 7 & 3 & 7 & 23.3 & 3.0 & 7.0 \\
\hline Siltstone & 6 & 40 & 7 & 3 & 7 & 28.0 & 3.6 & 8.4 \\
\hline Medium sandstone & 5 & 33 & 8 & 3 & 7 & 26.6 & 3.0 & 7.0 \\
\hline Mudstone & 4 & 27 & 7 & 3 & 9 & 18.6 & 2.4 & 7.2 \\
\hline Fine sandstone & 3 & 20 & 7 & 3 & 7 & 14.0 & 1.8 & 4.2 \\
\hline Medium sandstone & 3 & 20 & 8 & 3 & 7 & 16.0 & 1.8 & 4.2 \\
\hline Siltstone & 2 & 13 & 7 & 3 & 7 & 9.3 & 1.2 & 2.8 \\
\hline Mudstone & 5 & 33 & 8 & 3 & 7 & 26.6 & 3.0 & 7.0 \\
\hline Siltstone & 4 & 27 & 7 & 3 & 7 & 18.6 & 2.4 & 5.6 \\
\hline Fine sandstone & 2 & 13 & 7 & 3 & 7 & 9.3 & 1.2 & 2.8 \\
\hline Sandy mudstone & 2 & 13 & 7 & 2 & 8 & 9.3 & 0.8 & 3.2 \\
\hline Fine sandstone & 8 & 53 & 7 & 3 & 7 & 37.3 & 4.8 & 11.2 \\
\hline Mudstone & 4 & 27 & 8 & 3 & 7 & 21.3 & 2.4 & 5.6 \\
\hline Fine sandstone & 2 & 13 & 7 & 3 & 7 & 9.3 & 1.2 & 2.8 \\
\hline Coarse sandstone & 4 & 27 & 8 & 2 & 8 & 21.3 & 1.6 & 4.8 \\
\hline Fine sandstone & 11 & 73 & 7 & 3 & 7 & 51.3 & 6.6 & 15.4 \\
\hline Mudstone & 2 & 13 & 8 & 3 & 7 & 10.6 & 1.2 & 2.8 \\
\hline Siltstone & 4 & 27 & 7 & 3 & 7 & 18.6 & 2.4 & 5.6 \\
\hline Siltstone & 2 & 13 & 7 & 3 & 7 & 9.3 & 1.2 & 2.8 \\
\hline Fine sandstone & 4 & 27 & 7 & 3 & 7 & 18.6 & 2.4 & 5.6 \\
\hline Siltstone & 2 & 13 & 7 & 3 & 7 & 9.3 & 1.2 & 2.8 \\
\hline Mudstone & 6 & 40 & 8 & 3 & 7 & 31.9 & 3.6 & 8.4 \\
\hline Siltstone & 5 & 33 & 7 & 3 & 7 & 23.3 & 3.0 & 7.0 \\
\hline $2^{-2}$ coal seam & 2.5 & 20 & & & & & & \\
\hline Siltstone & 8 & 53 & 7 & 3 & 7 & 37.3 & 4.8 & 11.2 \\
\hline Fine sandstone & 7 & 47 & 7 & 3 & 7 & 32.6 & 4.2 & 9.8 \\
\hline $3^{-1}$ coal seam & 1.5 & 10 & & & & & & \\
\hline Siltstone & 2.5 & 17 & 7 & 3 & 7 & 11.6 & 1.5 & 3.5 \\
\hline
\end{tabular}

Note: the ratio of coal seam: river sand: gypsum : white powder $=26: 1: 5: 15$; the ratio of the loose layer in river sand : loess $=6: 4$.

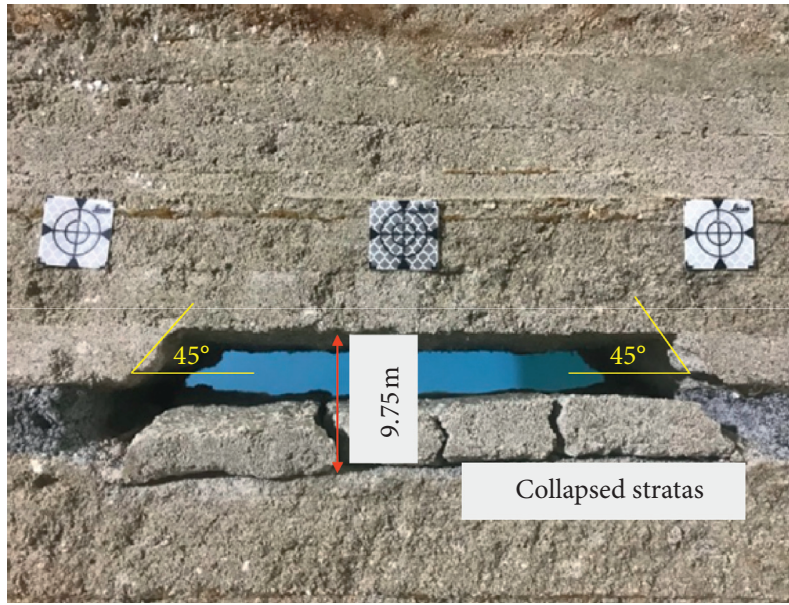

(a)

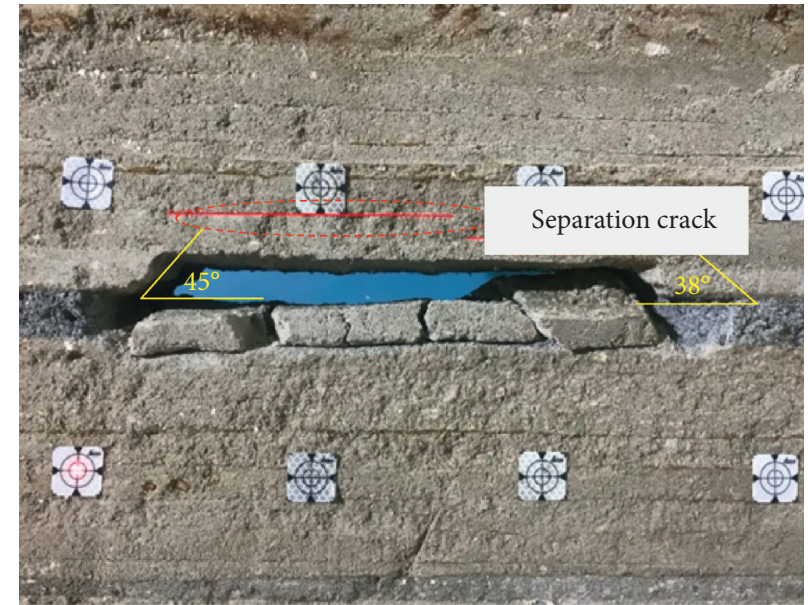

(b)

FIgUre 6: Continued 


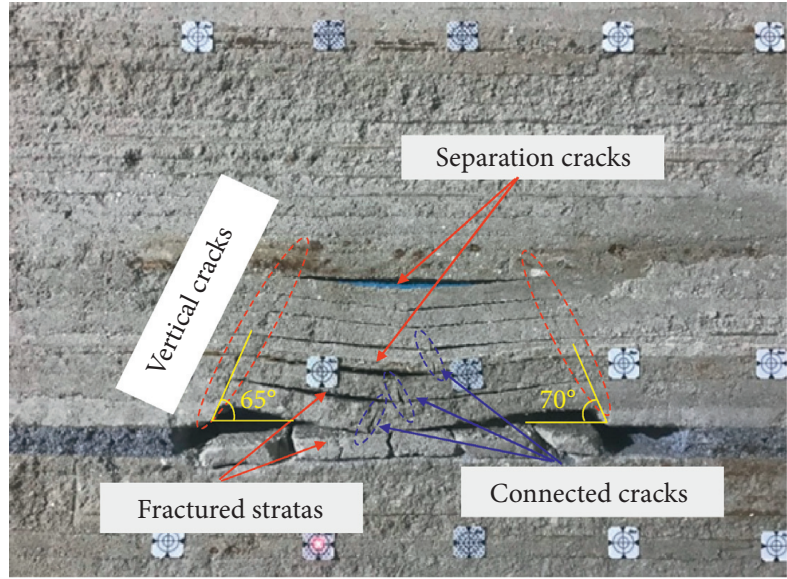

(c)

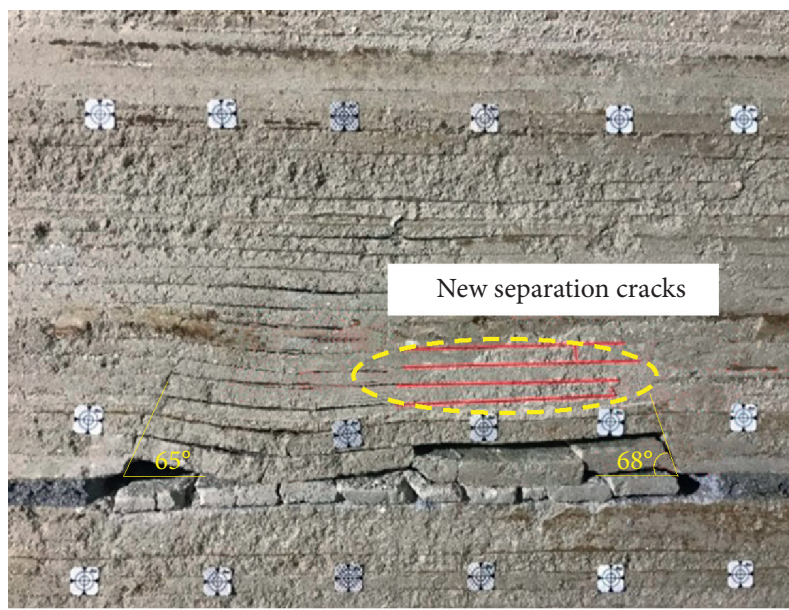

(e)

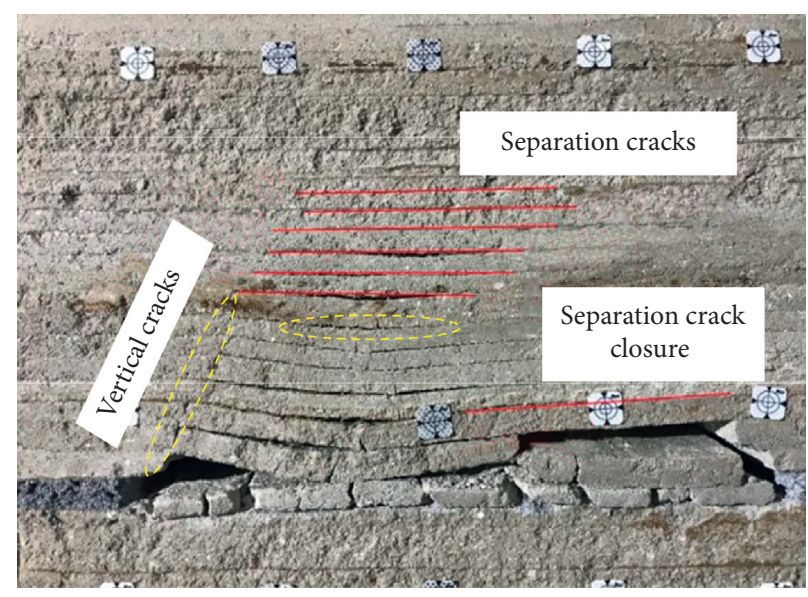

(d)

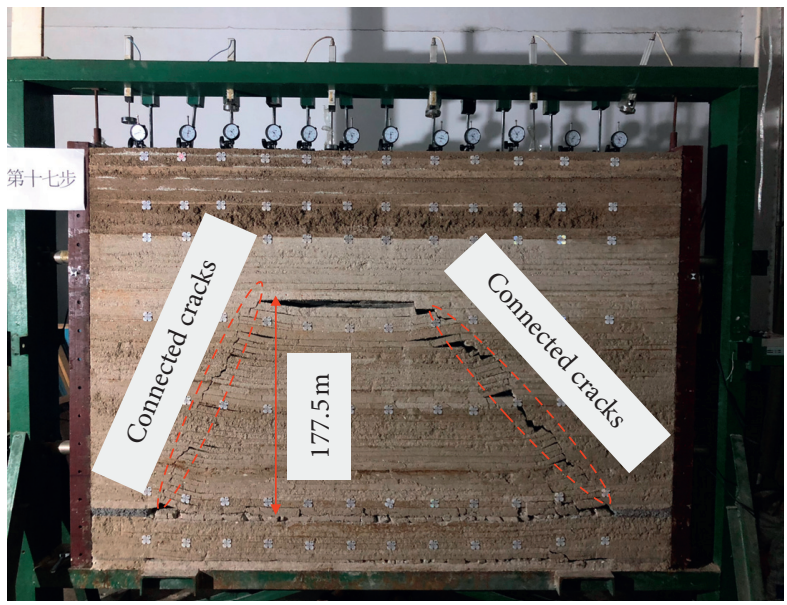

(f)

Figure 6: Water-conducting fractured zone development patterns using the similar simulation: (a) advanced $75 \mathrm{~m}$, (b) advanced $87.5 \mathrm{~m}$, (c) advanced $125 \mathrm{~m},(\mathrm{~d})$ advanced $150 \mathrm{~m}$, (e) advanced $175 \mathrm{~m}$, and (f) advanced $350 \mathrm{~m}$.

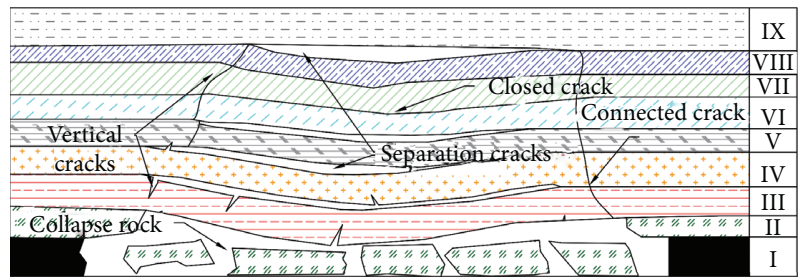

Figure 7: The overlying strata migration process of $2^{-2}$ coal seam mining.

(4) Slowly increasing stage: when the working face gradually reached the fully mined state, the goaf was compacted, and the separation cracks in the overlying strata were closed. At this time, the supporting role of the rock mass in the caved and fractured zones was prominent. The decline of the disturbance energy generated by the periodic fractures of the strata with height in the upward transmission process resulted in a decrease in the overburden damage speed. In this stage, the WCFZ developed slowly to its maximum.
(5) Stable stage: as the coal seam was mined, the stress change generated by the periodic collapse of the strata in the caved zone was not sufficient to continue damaging the strata above the top boundary of the WFCZ, so the height of the WCFZ developed to its maximum and remained stable.

3.3. Comprehensive Analysis. Figure 9 shows the damage pattern in the overburden strata caused by coal mining in the 112201 coalface. The overburden failure had two causes. The advancing separation crack was the main form of overburden failure from bottom to top. A roof beam structure that formed periodically was the main way that the overburden failure extended along the mining direction, and vertical cracks developed with the advancing. When the vertical cracks and separation cracks connected, the height of the WCFZ increased gradually.

As the mining proceeded, the height of the WCFZ was greater than that of other areas at the 112201 coalface, because the open-off cut and gateway areas were continuously stretched by stress. Therefore, the WCFZ assumed an 


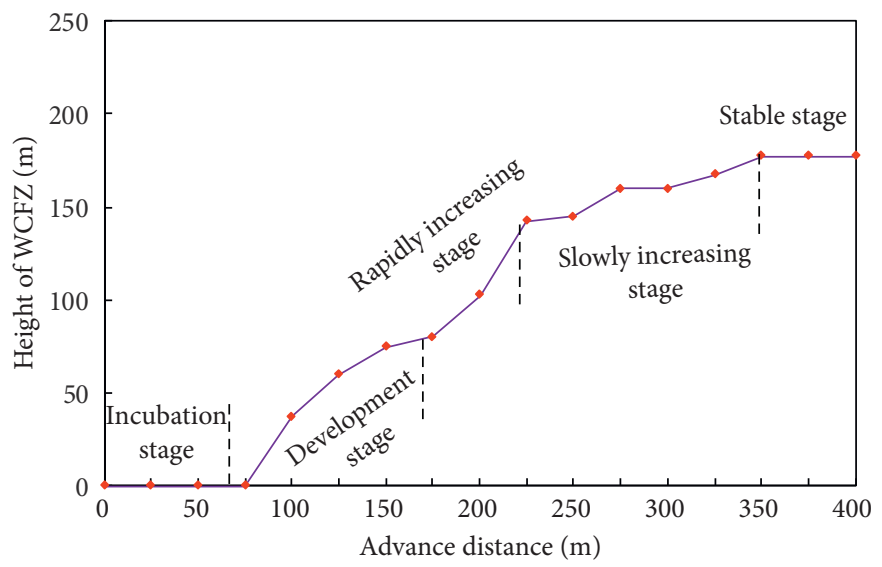

FIGURE 8: Variation in height of the WCFZ with advanced distance at the 112201 coalface.

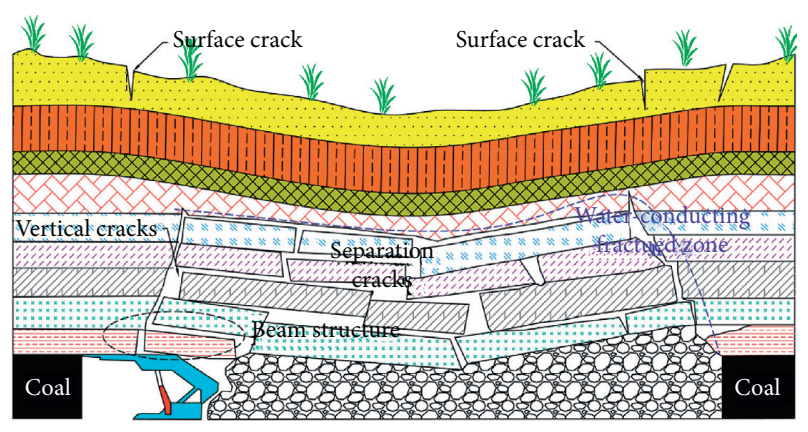

Figure 9: Damage diagram of overburden by coal mining.

inwardly convergent saddle shape. Also, the average width and drop of the surface cracks above the open-off cut and the gateway were higher than those in other areas, which also indicated that the overburden was relatively damaged.

\section{Conclusion}

The height of the WCFZ of the 112201 coalface in the 1 \# coal mine of Xiaobaodang was detected using field measurements that included fluid leakage and borehole TV images. Also, the formation mechanism of the overburden failure and the laws of the WCFZ were revealed by a similar-material simulation. The main conclusions were as follows.

(1) According to the detection results of fluid leakage and the borehole TV, the maximum height of the WCFZ of the 112201 coalface was $177.07 \mathrm{~m}$, and the value of $H_{w} / M$ was 30.53 . The WCFZ acquired an inward-convergent saddle shape different from that induced by shallow coal mining.

(2) Based on the similar-material simulation, the movement and failure characteristics of the overburden were revealed. The roof stratum collapsed first when the 112201 coalface was advanced to $75 \mathrm{~m}$, and the step distances of periodic collapse were $26.7 \mathrm{~m}$, which were mostly consistent with the measured values. The separation cracks caused by the uneven subsidence of overburden and the vertical cracks induced by beam structure fractures were the main forms of upward transmission, and they occurred along the mining direction of overburden failure. The main reason for the increase in height of the WCFZ was that the vertical and separation cracks connected.

(3) The development of the WCFZ of the 112201 coalface was comprised of five stages: incubation stage, development stage, rapidly increasing stage, slowly increasing stage, and stable stage. The duration of each stage was related to the lithology and mining technology.

\section{Data Availability}

The data used to support the findings of this study are included within the article.

\section{Conflicts of Interest}

The authors declare that there are no conflicts of interest regarding the publication of this paper.

\section{Acknowledgments}

This study was supported by the National Natural Science Foundation of China (No. 41472234), the Scientific Research Fund of Shaanxi Coal Chemical Industry Group (2018MHKJ-B-J-24) and the Basic Research Program of Natural Science of Shaanxi Province (2020ZY-JC-03).

\section{References}

[1] F. Du and R. Guo, "Development patterns of fractured waterconducting zones in longwall mining of thick coal seams-a case study on safe mining under the Zhuozhang River," Energies, vol. 11, p. 1856, 2017.

[2] H. Fan, L. Wang, Y. Lu, Z. Li, and K. Wang, "Height of waterconducting fractured zone in a coal seam overlain by thin bedrock and thick clay layer: a case study from the Sanyuan coal mine in North China," Environmental Earth Ences, vol. 79, pp. 1-11, 2020. 
[3] Y. Lu, B. Wu, M. He, L. Wang, and Z. Huang, "Prediction of fracture evolution and groundwater inrush from karst collapse pillars in coal seam floors: a micromechanics-based stress-seepage-damage coupled modeling approach," Geofluids, vol. 2020, Article ID 8830304, 21 pages, 2020.

[4] W. Zhai, W. Li, Y. Huang et al., "A case study of the water abundance evaluation of roof aquifer based on the development height of water-conducting fracture zone," Energies, vol. 13, no. 16, 4095 pages, 2020.

[5] L. Li, F. Li, Y. Zhang, D. Yang, and X. Liu, "Formation mechanism and height calculation of the caved zone and water-conducting fracture zone in solid backfill mining," International Journal of Coal Science and Technology, vol. 7, no. 1, pp. 208-215, 2020.

[6] S. Liu, W. Li, and Q. Wang, "Height of the water-flowing fractured zone of the jurassic coal seam in northwestern China," Mine Water and the Environment, vol. 37, no. 2, pp. 312-321, 2017.

[7] C. Tian, Y. Liu, X. Yang, and H. Yang, "Development characteristics and field detection of overburden fracture zone in multiseam mining: a case study," Energy Ence and Engineering, vol. 8, 2019.

[8] L. Yang, J. Xu, J. Fang, Z. Guo, and H. Song, "Risk evaluation of groundwater leakage in coal seam goaf: a case study in the lingxin mining area," Environmental Science and Pollution Research, 2020.

[9] S. Liu, S. Dai, W. Li, B. Han, and J. Luo, "A new monitoring method for overlying strata failure height in neogene laterite caused by underground coal mining," Engineering Failure Analysis, vol. 117, pp. 1-3, 2020.

[10] T. Zhu, W. Li, Q. Wang, Y. Hu, K. Fan, and J. Du, "Study on the height of the mining-induced water-conducting fracture zone under the Q2l loess cover of the jurassic coal seam in northern Shaanxi, China," Mine Water and the Environment, vol. 39, no. 1, pp. 57-67, 2020.

[11] B. Chen, S. Zhang, Y. Li, and J. Li, "Experimental study on water and sand inrush of mining cracks in loose layers with different clay contents," Bulletin of Engineering Geology and the Environment, vol. 80, pp. 673-678, 2021.

[12] W. Liu, "Experimental and numerical study of rock stratum movement characteristics in longwall mining," Shock and Vibration, vol. 2019, Article ID 5041536, 15 pages, 2019.

[13] S. Feng, S. Sun, Y. Lv, and J. Lv, "Research on the height of water flowing fractured zone of fully mechanized caving mining in extra-thick coal seam," Procedia Engineering, vol. 26, pp. 466-471, 2011.

[14] Y. Liu, Q. Liu, W. Li, T. Li, and J. He, "Height of waterconducting fractured zone in coal mining in the soil-rock composite structure overburdens," Environmental Earth Ences, vol. 78, pp. 1-13, 2019.

[15] H. Gu, W. Zhu, and X. Wang, "New method to predict the height of fractured water-conducting zone by location of key strata," Journal of China Coal Society, vol. 37, pp. 762-769, 2012.

[16] Y. Zhang, S. Cao, T. Wan, J. Wang, and J. Wang, "Field measurement and mechanical analysis of height of the water flowing fracture zone in short-wall block backfill mining beneath the aquifer: a case study in China," Geofluids, vol. 2018, pp. 1-12, 2018.

[17] G. Jing, Y. Wang, F. Zhou, and Z. Tan, "Numerical simulation study of water fracturing with different angle through beds holes based on RFPA (2D)," Coal Mining Technology, vol. 80, no. 5, pp. 673-678, 2018.
[18] X. Yu, K. Zhao, Q. Wang, Y. Yan, and J. Wang, "Relationship between movement laws of the overlaying strata and time space of the mined-out volume," Geofluids, vol. 2020, Article ID 2854187, 9 pages, 2020

[19] L. Li, K. Wu, Z. Hu, Y. Xu, and D. Zhou, "Analysis of developmental features and causes of the ground cracks induced by oversized working face mining in an aeolian sand area," Environmental Earth Sciences, vol. 76, p. 135, 2017.

[20] X. Liu, Y. Tan, J. Ning, C. Tian, and J. Wang, "The height of water-conducting fractured zones in longwall mining of shallow coal seams," Geotechnical\&Geological Engineering, vol. 33, pp. 693-700, 2015.

[21] G. Wang, M. Wu, R. Wang, H. Xu, and X. Song, "Height of the mining-induced fractured zone above a coal face," Engineering Geology, vol. 216, pp. 140-152, 2017.

[22] Z. Ren and N. Wang, "The overburden strata caving characteristics and height determination of water conducting fracture zone in fully mechanized caving mining of extra thick coal seam," Geotechnical and Geological Engineering, vol. 38, no. 1, pp. 329-341, 2020. 